\title{
Free Radicals: The types generated in biological system
}

\begin{abstract}
Free radicals are atoms or groups of atoms with an odd (unpaired) number of electrons (free and single electrons) orbit atoms or molecules. These molecules help to bind atoms together as they are attracted to each other. When oxygen molecules are split apart and turned into unstable free radicals in biological system, tend to find another molecules that bind with, this process is called oxidative stress. The risk of oxidative stress lies in the fact that the free oxygen atoms reach the genetic material in the DNA, affecting the structure and causing a mutation in the cell to turn into diseased or malignant cells. The aim of this descriptive mini review, generally, is to shed light on the main types of these vital Free radicals in cellular system that may be involved with some diseases.
\end{abstract}

Volume 5 Issue 3 - 2018

\author{
Chateen I Ali Pambuk, Fatma Mustafa \\ Muhammad \\ University of Tikrit, Iraq
}

\begin{abstract}
Correspondence: Chateen I Ali Pambuk, PhD Medical Immunology, (College of Dentistry/University of Tikrit), Iraq, Tel +009647701808805, Email dr.chaten2@yahoo.com
\end{abstract}

Received: October 02, 2018 | Published: November 08, 2018

Keywords: free Radicals, singlet $\mathrm{O}_{2}$, hydroxyl radical

\section{Introduction}

\section{Free radicals}

Organic free radicals are produced continuously in biosystems, white blood cells, through mechanisms are involved in detoxification following exposure to certain toxic substances or radiation. Because of their hyperactivity they vigorously attack vital cellular components causing serious damage that can lead to cellular death, where their attacks on membrane phospholipids disrupt the activity of the cell membrane, and their destruction of proteins disrupts the important. Enzymatic functions. In addition to their ability to change the nature of DNA they affect the construction of proteins, and an alert for the uncontrolled division of distinct cancer cells. ${ }^{1,2} \mathrm{~A}$ free radical is defined as an atom or a neutral or charged molecule contained in its external orbit, unpaired electron, ${ }^{3,4}$ which is unstable molecule interact with more stable molecules to pair their electron by acquiring an electron (acting as oxidizer) or give up an electron (acting as a reducer). This interaction leads to the formation of new radicals, which explains the ability of one negative electron to destroy the cell. ${ }^{2}$ Oxidative stress in the biological system is defined as an imbalance between antioxidants and oxidation generators, this imbalance is due to the excessive production of oxidation generators and/or lack of antioxidants. Often, oxidizing molecules cause cellular and tissue damage, often irreversible. ${ }^{5}$

\section{Types of free radicals or active forms of oxygen}

We distinguish active forms of oxygen and are small particles that do not contain carbon atoms such as $\mathrm{O}_{2} .-\mathrm{NO}, . \mathrm{OH}$ and oxygen derivatives of unsaturated fatty acids such as RO. And ROO as well as some non-radical oxygen derivatives such as: $\mathrm{H}_{2} \mathrm{O}_{2}$, Singlet oxygen (anion hypochlorite - OCl) (Held, 2012)

\section{Superoxide anion $\mathbf{O}_{2}$}

Is a negatively charged single radical, resulting from monoclonal reduction of molecular oxygen that acquires an electron during a reaction that requires energy. This reaction occurs in the presence of the NADPH oxidase enzyme during phagocytosis or mitochondrial cytochrome oxidase activity during the cellular respiration process, oxidase xanthine (reperfusion - ischemia) or P450 cytochrom hepatic, which interferes with the metabolism of some exotic molecules, is considered an anoxide + low reaction, In the body, reacts in the presence of SOD with $\mathrm{H}$ giving hydrogen peroxide $\mathrm{H}_{2} \mathrm{O}_{2}$ and $\mathrm{O}_{2}{ }^{1,2}$

\section{Hydrogen peroxide $\mathrm{H}_{2} \mathrm{O}_{2}$}

Secondary is composed of the dismutation reaction of the superoxide anion, is not considered a free radical but highly reactionary $2+$ and has high oxidation capacity, decomposes in the presence of Fenton $\mathrm{F}$, to give $\mathrm{OH}$ and $\mathrm{OH}$ hydroxy. Highly toxic. Hydrogen peroxide $\mathrm{H}_{2} \mathrm{O}_{2}$ also results from the reduction of oxygen by a large number of enzymes dehydrogenase, urinase, xanthine oxidase, NADH deshydrogenase, Acyl Co Adeshydrogenase, such as monaamine-oxydas. ${ }^{6}$

\section{Hydrogen oxide $\mathrm{OH}$}

Resulting from $\mathrm{H}_{2} \mathrm{O}_{2}$ according to the Weiss-Haber interaction: The hydroxyl root is more interactively than an oxidous one by thousand times. It stimulates the production of new radical roots by removing a hydrogen atom or by transporting its individual electron. The cell is formed by oxidase xanthine, In the microsoum. ${ }^{1,6}$

\section{Single oxygen $O$,}

Is the irritating form of molecular oxygen, produced in particular by the photochemical activation of oxygen, in a small amount compared to the aforementioned radicals, acts as free radicals.

\section{RO. Radicals and the peroxyl ROO}

The oxidation of unsaturated fatty acids is formed by anion beta oxidationsuperoxide, the radical, ${ }^{1,2,6}$ singular oxygen and hydroxyl

\section{Nitrogen oxide}

Produced in the lining of the vessels, neurons and large macrophages, is derived from the amino acid arginine in the presence of NO Synthase, a gas that plays a fundamental physiological role, but its presence can be very toxic, interacting with an anode superoxide generator ONOO (peroxynitrite). The latter one can damage proteins and convert them into two toxic compounds, the hydroxyl radical and 
$\mathrm{NO}_{2}$, and attack tyrosine and convert it to nitrotyrosine- $3,{ }^{1,7,8}$ the latter is noticed in many diseases such as inflammation and gout. ${ }^{7}$

\section{Conclusion}

Free radicals are atoms or groups of atoms with free and single electrons orbit atoms or molecules. These molecules help to bind atoms together as they are attracted to each other. When oxygen molecules are split apart and turned into unstable free radicals in biological system, tend to find another molecules that bind with, this process is called oxidative stress. The risk of oxidative stress lies in the fact that the free oxygen atoms reach the genetic material in the DNA, affecting the structure and causing a mutation in the cell to turn into diseased or malignant cancerous cells. ${ }^{9,10}$

\section{Acknowledgements}

None.

\section{Conflict of interest}

The authors declare that there is no conflict of interest.

\section{References}

1. Valko M, Rhodes CJ, Moncol J. et al. Free radicals, metals and antioxidants in oxidative stress-induced cancer. Chem Biol Interact 2006;160(1):1-40.
2. Dodet B. La chasse aux radicauxlibresoxygénés. Biofutur. 1991;101:2334.

3. Kanadaswami C, Lee L, Lee PP, et al. The Antitumor Activities of Flavonoids. In vivo. 2005;19(5): 895-910.

4. Valko M, Leibfritz D, Moncol J, et al. Free radicals and antioxidants in normal physiological functions and human disease. Int J Biochem Cell Biol. 2007;39:44-84.

5. Tung EW, Winn LM. Valproic acid-induced DNA damage increases embryonic p27KIP1 and caspase-3 expression: A mechanism for valproicacid induced neural tube defects. Reprod Toxicol. 2011;32(3):255-260.

6. Clavel JP, Emerit J, Thuillier A. Lipid peroxydation. etradicauxlibres, Role en biologiecellulaire et en pathologie. Path Biol. 1985;33(1):61-69.

7. Halliwel B. Antioxidants and human disease: General Introduction. Nutrition Revieus. 1997;55(1):544-552.

8. Halliwell B. Free radicals, antioxidants, and human disease: curiosity, cause, or consequence? Lancet. 1994;344(8924):721-724.

9. Kehrer JP, Robertson JD, Smith CV. Free Radicals and Reactive Oxygen Species. Comprehensive Toxicology. 2010;1:277-307.

10. Held P. An Introduction to Reactive Oxygen Species Measurement of ROS in Cells. Bio Tek Instruments, Inc; 2012. 